\title{
Evaluation of cloudiness over Monte San Valentín, Northern Patagonia Icefield, from 2000 to 2008 using MODIS satellite images: implications for paleoclimate investigations from ice cores
}

\author{
Françoise VIMEUX, ${ }^{1,2}$ Fabienne MAIGNAN, ${ }^{2}$ Corentin REUTENAUER, ${ }^{2}$ \\ Bernard POUYAUD ${ }^{1}$ \\ ${ }^{1}$ Institut de Recherche pour le Développement (IRD), Laboratoire HydroSciences Montpellier (HSM), \\ UMR 5569 (CNRS-IRD-UM1-UM2), 34095 Montpellier, France \\ ${ }^{2}$ Institut Pierre-Simon Laplace, Laboratoire des Sciences du Climat et de l'Environnement, UMR 8212 (CEA-CNRS-UVSQ), \\ CE Saclay, Orme des Merisiers, Bâtiment 701, 91191 Gif-sur-Yvette Cedex, France \\ E-mail: Francoise.Vimeux@Isce.ipsl.fr
}

\begin{abstract}
An unexpectedly low annual net accumulation $\left(20 \mathrm{~cm}\right.$ w.e. $\left.\mathrm{a}^{-1}\right)$ has been inferred from analyses of a firn core extracted from Glaciar Monte San Valentín, Northern Patagonia Icefield $\left(46^{\circ} 35^{\prime} \mathrm{S}, 73^{\circ} 19^{\prime} \mathrm{W} ; 3747 \mathrm{~m}\right.$ a.s.I.). We test a hypothesis linking the low accumulation to a frequent lack of cloud cover over the mountain range at this altitude. The cloudiness over Monte San Valentín and surrounding regions is examined using $\sim 3000$ daily MODIS satellite images from 2000 to 2008 . The visual evaluation of the synoptic situation leads to the definition of a daily cloudiness index (EI) for the San Valentín summit and for the regions to the southwest (SW) and northeast (NE). We check its robustness by applying different tests and comparisons. Three levels are assigned for the El: 'clear' $(E I=0)$, 'cloudy' $(E I=1)$ and 'mixed' $(E I=0.5)$. The results show that the SV cloud cover is similar to the regional cloudiness for more than half the year $(54 \%)$ and that the case in which the San Valentín summit is clear while both SW and NE regions are cloudy is exceptional (2\%). As clouds are necessary to provide precipitation, we show that the low annual net accumulation cannot be explained by an uncommon low cloudiness. This result implies that net accumulation inferred from ice cores in this Andean region must be cautiously interpreted. We also point out that the Andes at this latitude acts as an orographic barrier but without a total blocking of air masses.
\end{abstract}

\section{INTRODUCTION}

In 2005, a shallow firn core was drilled on the summit of Monte San Valentín (46³5’ S, 7319’ W; 3747 ma.s.l.), Northern Patagonia Icefield (NPI), to evaluate the potential of the site for future paleoclimate investigations. Chemical and radionuclide measurements led to the reconstruction of an annual net accumulation of $20 \mathrm{~cm}$ w.e. over the past 45 years (Vimeux and others, 2008). This is a much smaller value than expected from previous work, namely: (1) other published data arising from firn-core studies for both the NPI and Southern Patagonia Icefield (SPI), ranging from $\sim 1$ to 14 m w.e. $\mathrm{a}^{-1}$ (Yamada, 1987; Aristarain and Delmas, 1993; Rott and others, 1998; Matsuoka and Naruse, 1999; Popovnin and others, 1999; Shiraiwa and others, 2002; Schwikowski and others, 2006) and (2) annual precipitation estimates in the NPI area of 3-10 mw.e. according to isolated meteorological observations (Fujiyoshi and others, 1987), hydrological models (Escobar and others, 1992) and European Centre for Medium-Range Weather Forecasts (ECMWF) Interim Re-analyses (ERA-I) including the San Valentín summit (available from ECMWF at $0.5^{\circ}$ and over the 2000-07 period; Berrisford and others, 2009).

Net accumulation is total accumulation (precipitation and blowing-snow redeposition) minus ablation (wind erosion, melting or sublimation). Two hypotheses have been suggested to explain such low accumulation at the site:

1. Strong wind erosion may cause low accumulation, although no alteration of isotopic or chemical signals is observed (Vimeux and others, 2008). According to US National Centers for Environmental Prediction (NCEP)/ US National Center for Atmospheric Research (NCAR) reanalyses (Kalnay and others, 1996) at $600 \mathrm{mbar}$ (roughly corresponding to the glacier altitude), annual mean wind speed over the 1948-2005 period is $15 \mathrm{~m} \mathrm{~s}^{-1}$ on the NPI and can attain $>20 \mathrm{~m} \mathrm{~s}^{-1}$ from December to April in extreme events. However, this value is of the same order as wind-speed reanalyses, and in situ measurements on the SPI for which high accumulation is found (Shiraiwa and others (2002) found similar windspeed values on Glaciar Tyndall, SPI, where an annual accumulation of $\sim 2 \mathrm{~m}$ w.e. has been estimated).

2. Low accumulation may result from a low precipitation rate due to the combined effect of altitude (NPI elevation is $1000-1500 \mathrm{~m}$ and San Valentín is the highest summit, 1000-2000 $\mathrm{m}$ higher than other drilling sites) and the mountain range acting as a barrier (annual precipitation decreases from $\sim 7000 \mathrm{~mm}$ on the Chilean coast to $<200 \mathrm{~mm}$ east of the Argentine Andes, with a significant spatial gradient on the icefield (Carrasco and others, 2002; Schneider and others, 2003; Villalba and others, 2003). The estimated precipitation decrease from west to east across the SPI is $20-50 \%$ according to Escobar and others (1992) and Carrasco and others (2002). Furthermore, the San Valentín is located at the northeast corner of the icefield, $\sim 30 \mathrm{~km}$ east of the first orographic obstacles encountered by Pacific air masses). Both 
Table 1. Resolution and bandwidth for the three MODIS channels used

\begin{tabular}{lccc}
\hline Channel & $\begin{array}{c}\text { Bandwidth } \\
\mathrm{nm}\end{array}$ & $\begin{array}{c}\text { Resolution } \\
\mathrm{m}\end{array}$ & Color \\
\hline 1 & & & \\
2 & $620-670$ & 250 & Red \\
6 & $841-876$ & 250 & $\begin{array}{c}\text { Green } \\
\text { Blue }\end{array}$ \\
\hline
\end{tabular}

orographic features are expected to strongly reduce the precipitation rate and the cloud development at the altitude of Monte San Valentín. However, as there is no meteorological station at this altitude in Patagonia, we have no information on precipitation rate.

Although this second hypothesis could appear unlikely in view of the expected annual precipitation and observed wind speeds, we started to consider it seriously following discussions with LAN Airlines pilots while preparing the 2007 field campaign (personal communication from B. Pouyaud and G. Casassa, 2006). Around ten daily flights cross the NPI at $>10000 \mathrm{~m}$ a.s.l. and it is often observed that only the San Valentín summit is visible above a regional cloud cover extending both west and east on the lower icefields.

In this paper, we test the hypothesis that precipitation rate on the San Valentín summit is low relative to surrounding regions. We base our estimates of daily cloudiness on satellite images derived from Moderate Resolution Imaging Spectroradiometer (MODIS) data from 2000 to 2008.

\section{DATA AND METHODOLOGY}

\subsection{Data}

The San Valentín summit is a plateau with an east-west extension of $1.5 \mathrm{~km}$ spanning an altitude range of 3700 $4030 \mathrm{~m}$. The need for daily, high (or at least medium) spatial resolution observations of this glacier and its surroundings led us to select the MODIS satellite sensor. This provides daily reflectances in seven channels for land surface applications (Vermote and others, 2002) at a spatial resolution of 250 or $500 \mathrm{~m}$, depending on the channel. These are surface reflectances, corrected from atmospheric effects (absorption and diffusion by gases and aerosols). There are currently two operating MODIS sensors, one on board the Terra satellite in orbit since December 1999 and the second on board the Aqua satellite since May 2002. The MODIS reflectances are gridded on a sinusoidal projection, divided into $10^{\circ} \times 10^{\circ}$ tiles. Daily files can be downloaded through the Land Processes Distributed Active Archive Center (LP DAAC) web page (https://lpdaac.usgs.gov/lpdaac/get_data). Channel 1 (620-670 nm) and channel $2(841-876 \mathrm{~nm})$ data are available at a $250 \mathrm{~m}$ spatial resolution in the MODG09Q products for Terra (MYDG09Q for Aqua), and the other channels are available at a $500 \mathrm{~m}$ spatial resolution in the MODG09GA products for Terra (MYDG09A for Aqua), along with a Cloud Mask included in the $1 \mathrm{~km}$ Quality Assurance field. The geographical coordinates of the San Valentín summit correspond to the h12v13 MODIS tile.

We examined other available products. Thermal observations of MODIS at night have a $5 \mathrm{~km}$ spatial resolution, so cannot be used to study the Monte San Valentín cloudiness.
Similarly, the meteorological satellites GOES-East (Geostationary Operational Environmental Satellites) are not useful for this study because of a spatial resolution problem. The finest resolution of $1 \mathrm{~km}$ is only available for the visible channel for nadir viewing. The resolution becomes coarser as one goes south, to the edges of the satellite image, and San Valentín is clearly located near the south edge

\subsection{Methodology}

\subsubsection{False-color composite images}

We first define an area of interest around the San Valentín summit, adding a width of $94 \mathrm{~km}$ north-northeast to southsouthwest, and a larger width of $141 \mathrm{~km}$ north-northwest to south-southeast (total area $>14000 \mathrm{~km}^{2}$ ). We divide this area in two along the Andean ridge, defining a southwest (SW) zone containing the Pacific Coast and a northeast (NE) zone separated from the Pacific Ocean by the mountain range (cyan line in Fig. 1). Our aim is to clearly separate the Chilean coast (windward) from the Argentine side (leeward). As our objective is to evaluate the difference in cloudiness between the San Valentín and surrounding regions at lower altitude, we also define the San Valentín (SV) zone according to its GPS coordinates (small white parallelogram in Fig. 1).

To study the cloudiness of this area, we create false-color composite images using the $250 \mathrm{~m}$ spatial resolution channels 1 and 2 in association with the $500 \mathrm{~m}$ spatial resolution channel $6(1628-1652 \mathrm{~nm}$, in the shortwave infrared (SWIR) band), projected respectively in the red, green and blue color channels of the display device (Table 1). Figure 1 shows such an image for different cloud covers. Water surfaces appear in black, clear land surfaces in green, snow and ice in light yellow (due to the use of channel 6, which can differentiate between snow/ice and liquid water clouds because in the SWIR band most liquid water clouds have a high reflectance while ice and snow have a low reflectance (Salomonson and Appel, 2004)) and liquid water clouds in white.

\subsubsection{The Eye Index (EI)}

To explore the daily cloudiness from 2000 to 2008 (3074 images), we define an index representing the cloudiness. The need to compare the cloudiness over the SV zone with the SW and NE zones using the same index prevents us from using a classical algorithm for cloud detection (section 2.3). We thus proceed to a visual evaluation of cloudiness for each MODIS image, where a human eye observes daily false-color composite images of the total area. The observer assigns for each zone (SV, SW and NE), and for each daily image, one of three levels called the 'Eye Index' (EI): clear $(E I=0)$, cloudy $(E I=1)$ or 'mixed' $(E I=0.5)$. Examples of different situations are shown in Figure 1c-e. An El of 0 is assigned when the considered zone is entirely clear or when iced clouds are detected (section 2.4). An El of 1 is assigned when the considered zone is entirely cloudy. For the other cases, an El of 0.5 is assigned. There are two exceptions: when a very small accumulation of clouds in a corner of the image is exhibited or when we detect a very small cloud, we attribute an $\mathrm{El}$ of 0 . In contrast, when almost all the considered region is cloudy, we attribute an El of 1 .

We thus obtain a daily reconstruction of cloudiness from 2000 to 2008. The validity of our basic method is discussed next. 


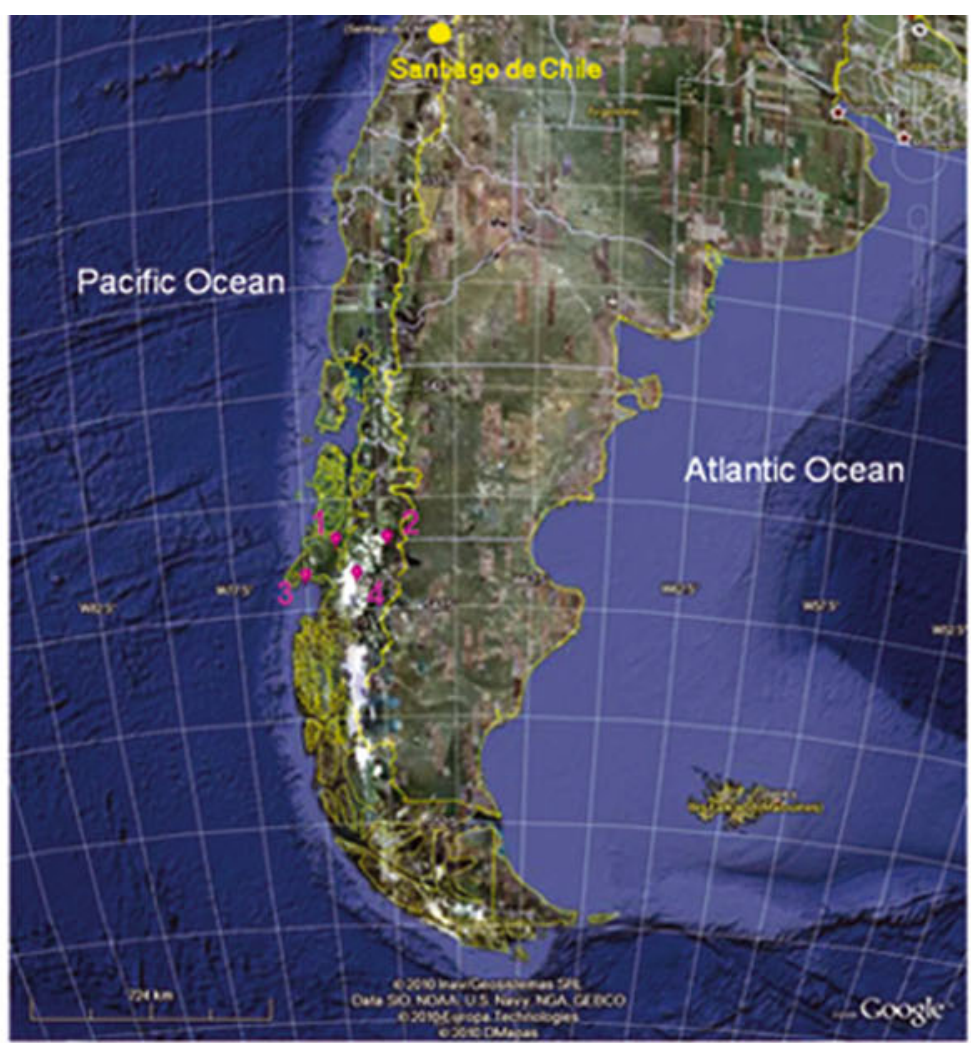

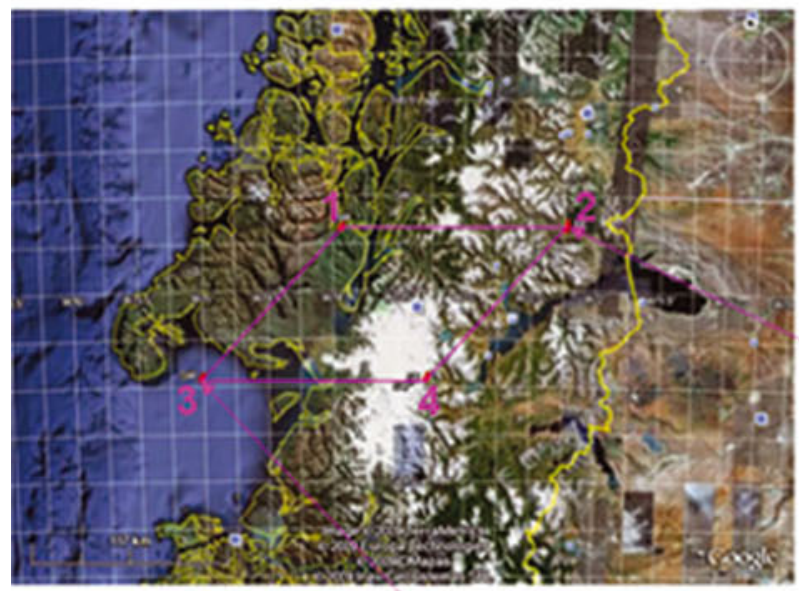

b

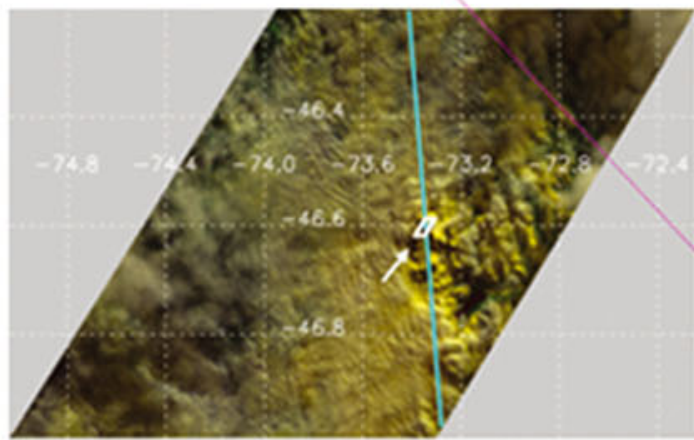

d

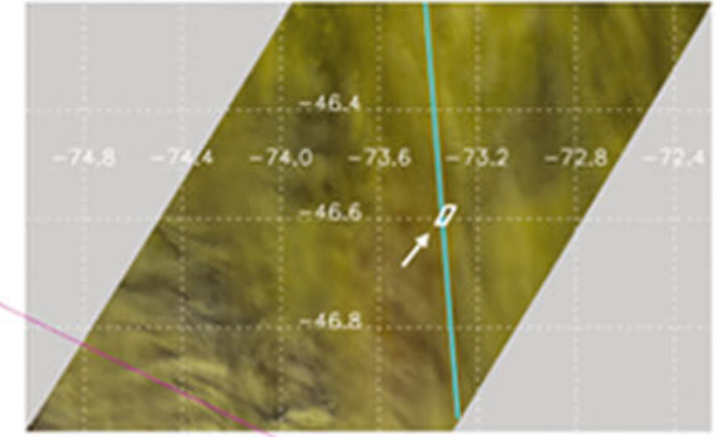

c
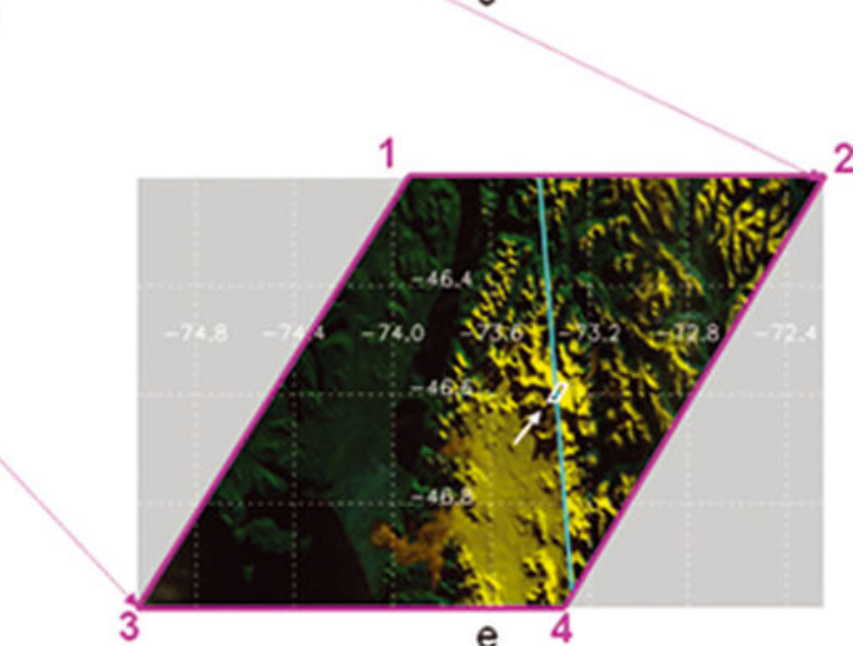

Fig. 1. (a) Picture from Google Earth showing southern South America with our studied zone (magenta zone). (b) Picture from Google Earth showing the NPI and our studied zone (magenta zone). (c-e) Images (color composites) created from the MODIS/Terra reflectances in channels $1(620-670 \mathrm{~nm}), 2(841-876 \mathrm{~nm})$ and $6(1628-1652 \mathrm{~nm})$. Latitudes and longitudes are superimposed in white, and the diagonal in cyan is used to separate the southwest (SW) region and the northeast (NE) region. The San Valentín (SV) is included in the small white parallelogram indicated by the white arrow. Each panel illustrates a specific situation: (c) cloudy state for the three zones $(E I=1)$; $(d)$ cloudy 


\subsection{Validation of EI}

To validate the El method, we propose four independent validations.

\subsubsection{The Cloud Index (CI)}

We have created for both the SW and NE zones a very simple Cloud Index $(\mathrm{Cl})$ obtained independently of the El. The CI calculation is based on the fact that reflectances in channels 1, 2 and 6 are much lower for clear than for cloudy pixels. The $\mathrm{Cl}$ is calculated as a simple mean over the three channels of the MODIS false-color image and over all the pixels of the $\mathrm{SW}$ and $\mathrm{NE}$ zones. In this way the $\mathrm{Cl}$ gives us the level of cloudiness of the scene. The lower the $\mathrm{Cl}$, the clearer the scene, except in the presence of snow/ice pixels. However, we know that the simple mean of channels 1, 2 and 6 cannot differentiate cloud from snow/ice as their reflectances are similar for channels 1 and 2. Thus, we take advantage of the $1 \mathrm{~km}$ Quality Assurance field. The latter includes the MODIS Cloud Mask with four states, 'clear', 'cloudy', 'mixed' and 'assumed clear', as well as an independent 'snow/ice' flag for each pixel. We can thus calculate a mean reflectance for each pixel state. The mean $\mathrm{Cl}$ value obtained from all 'clear and not snow/ice' pixels is low (25) and the mean $\mathrm{Cl}$ value obtained from all cloudy pixels is significantly higher (80) as expected (there is no significant difference between the SW and $\mathrm{NE}$ zones). The mean $\mathrm{Cl}$ value for snow/ice pixels is quite high (65) whereas they should be clear pixels (and will disturb our clear/cloudy ratio). We thus assign these pixels the preceding mean $\mathrm{Cl}$ 'clear and not snow/ice' value of 25 . There is no $\mathrm{Cl}$ for the SV zone, as the latter is too small to produce a significant reflectance mean.

The $\mathrm{Cl}$ may be sensitive to non-corrected effects:

1. Surface reflectances may vary depending on the acquisition geometry and vegetation (Maignan and others, 2004). We verify that this has negligible impact on the $\mathrm{Cl}$. As a first test, we calculate the standard deviation over 1 year of the $\mathrm{CI}$ for the NE and SW zones and we do the same considering only clear pixels. The former is three to four times higher than the latter, demonstrating that directional or vegetation-growth effects are of second order compared with the impact of clouds on the $\mathrm{Cl}$. As a second test, we calculate the mean visible reflectance (channel 1) and the mean near-infrared reflectance (channel 2) over the NE and SW zones and verify that they share the same seasonal behavior. An influence of vegetation growth should yield a decrease in channel 1 associated with an increase in channel 2.

2. The $\mathrm{Cl}$ may be sensitive to shadows generated by the topography, depending on the acquisition geometry (Lopez and others, 2008). Indeed, as the local acquisition time is quasi-constant, the solar zenithal angle exhibits a seasonal cycle. The only region where we observe such a topographic effect is the SV zone, where the rocky side is more or less dark depending on the solar zenithal angle. However, as this zone is too small, we do not calculate the $\mathrm{Cl}$ over the San Valentín. For the observer, the contrast between the rocky and the snowy side of the San Valentín remains strong enough year-round to be used as a criterion for the El discrimination between clear and cloudy scenes.

To check our $\mathrm{Cl}$, we also calculated a cloud index based only on the MODIS Cloud Mask classification for the SW and NE zones over our first complete year, 2001 (Cl-Cloud Mask). We attribute to each pixel a numerical value of 0 in the clear cases ('clear', 'assumed clear' and 'snow'), 2 in the 'mixed' case and 4 in the 'cloudy' case, and for each zone we calculate the corresponding average over all pixels. The $\mathrm{Cl} / \mathrm{Cl}-\mathrm{Cloud}$ Mask correlations, $r$, are 0.88 and 0.91 for the SW and NE zones respectively, which is highly significant $(p<0.001)$.

We have compared the daily $\mathrm{EI}$ and $\mathrm{Cl}$ values for the SW and NE zones for each year. The covariance, $r^{2}$, is always $>70 \%$ and increases to $80-85 \%$ for the 5 day running average $(p<0.001)$.

\subsubsection{Calculation of normalized-difference snow index (NDSI)}

As a validation of the $\mathrm{El}$ for the SV zone, we use the normalized-difference snow index (NDSI) which is calculated as a normalized difference between the spectral reflectance values of visible and SWIR bands (Hall and others, 1995). We calculate this index for the complete first year, 2001, using channels 1 and 6. A low value of NDSI will indicate a cloudy pixel whereas a high value is indicative of snow/ice presence. It is worth noting that vegetation and surface water will introduce errors in the NDSI detection skills (Parajka and Blöschl, 2006; Shreve and others, 2009) and furthermore we are not interested in determining the snow-cover extent; we are interested in the cloud cover. That is why we do not use this index for both SW and NE zones. The correlation between the EI and the NDSI over the SV zone, $r$, is -0.85 and increases to -0.90 $(p<0.001)$ for the 5 day running average (we expect a negative correlation as the NDSI/nebulosity is inverse to the $\mathrm{El} /$ nebulosity relationship).

\subsubsection{Comparison between in situ pictures and satellite images}

We also compare some in situ pictures from 2000-08 with the corresponding MODIS satellite images. We have 40 in situ pictures of the San Valentín site, corresponding to 19 days (we have 10 days with at least two in situ pictures at two different hours). On each in situ picture we can evaluate the SV cloud cover. Most of the time, the cloud cover of the region from which the picture is made is visible. When several pictures are available for one day, we choose the one closest to the satellite acquisition hour (so our comparison relies on $n=19$ ). Figure 2 illustrates the comparison for three days in 2007 with different Els. All of the in situ pictures showing a clear sky $(E I=0)$ or a thick cloud cover $(E I=1)$ for the SV zone $(n=17)$ have been assigned to the correct El. We obtain the same correspondence for the NE $(n=8)$ and SW $(n=1)$ zones when they are visible. This result is of primary importance, as our initial question deals with the occurrence of clear sky in the SV zone relative to the two other zones. We have two in situ pictures for which an El of 0.5 is expected for the SV zone. One of them compares with an El of 0 on the MODIS satellite images. We observe that this picture was obtained in late evening $(1900 \mathrm{~h})$, much later than the MODIS visit (section 2.4). It is important to note that our comparison is valid for clear or cloudy sky (El of 0 or 1 ) as we have only two pictures (11\%) with an El of 0.5.

Finally, we organized two field campaigns in 2006 and 2007 for which we have direct observations on the San Valentín summit for each day (i.e. 4 and 13 days respectively). The comparison between observations at the summit 


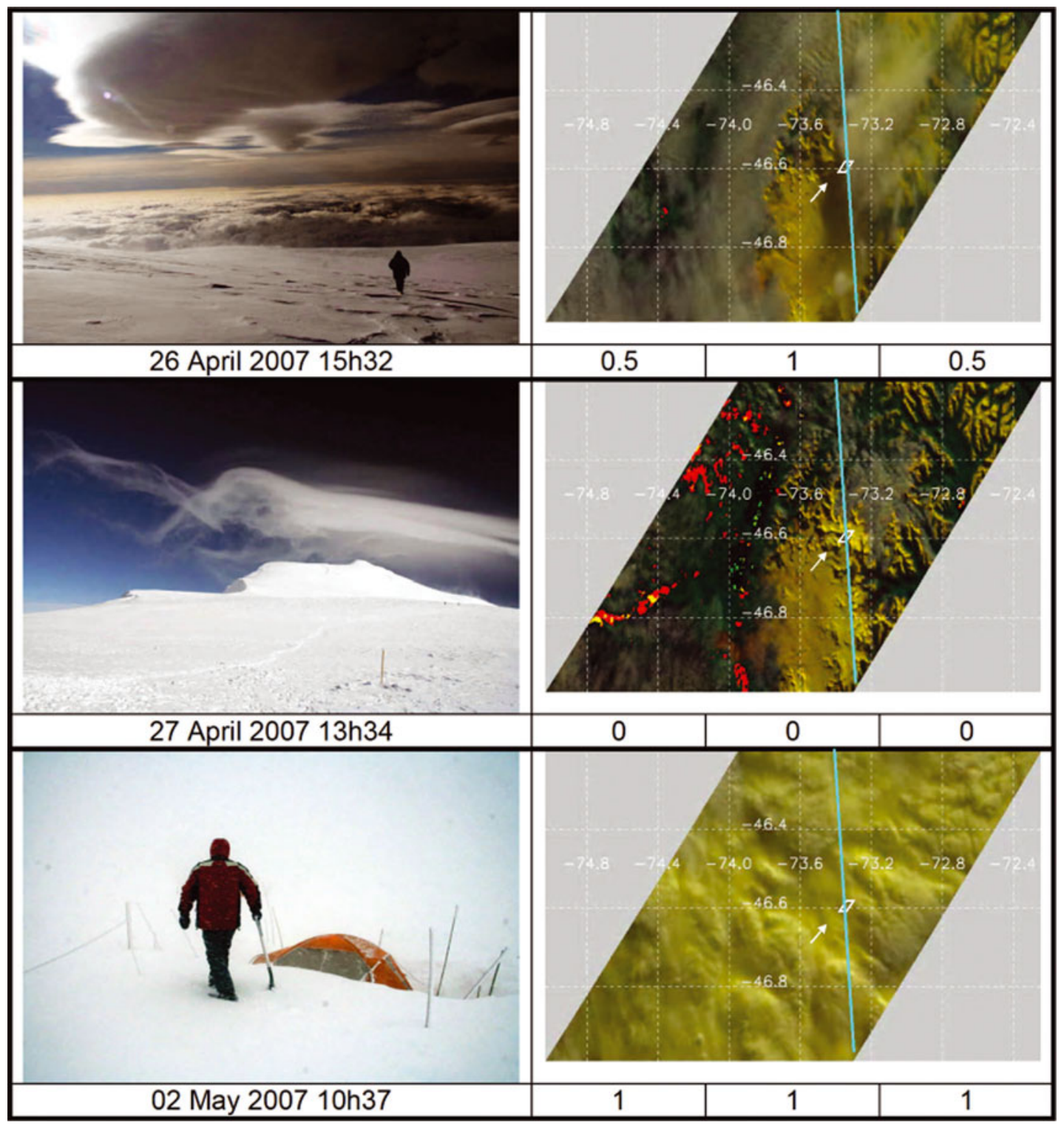

Fig. 2. Comparison between MODIS satellite images and in situ pictures for 26 and 27 April 2007 and 2 May 2007. For MODIS satellite images, we indicate the assigned El for each zone. For 26 April 2007 we can see an example of El $=0.5$. In situ pictures are courtesy of P. Ginot. (Red pixels appear when some reflectance measurements are missing.)

made close to the time of the satellite pass and MODIS images leads to a score of $100 \%$.

\subsubsection{El: observer-dependent?}

The El could be highly observer-dependent despite the high correlations with the $\mathrm{Cl}$. To evaluate the observer influence, two observers computed this index for the first complete year, 2001, which has 332 available images. The number of similar El levels is 240 (72\%), 205 (62\%) and 274 (83\%) for the SW, NE and SV zones respectively. The differences mainly occur for the attribution of an El of 0.5 versus an El of 1 and conversely, with no impact on the clear-state attribution for the SV zone.

Our initial question leads us to estimate the cloudiness for the SV zone in relation to the surrounding areas. We thus need to determine the nebulosity for our three zones using the same index. The El appears to be the most suitable candidate as we were able to validate it in different ways for the different zones. Nonetheless our method has some important caveats which we describe next.

\subsection{Possible caveats of the methodology}

We are aware that our methodology leads to important limitations, so important caveats must be mentioned:

1. The MODIS satellite image acquisition occurs twice per day at $1030 \mathrm{~h}$ for Terra and $1330 \mathrm{~h}$ for Aqua (local time). A possible shift occurs around this time, depending on the acquisition geometry. We estimated this shift to be less than \pm 1 hour by examining the solar zenithal angle evolution over 1 year. We also compared a former version of our $\mathrm{Cl}$ relying on channels 1, 2 and 3 for Terra and Aqua (channel 6 is not available for Aqua) for 2005 (341 used days). We found no significant evolution of the nebulosity either in the SW or in the NE region between the two acquisition times (in 2005, $n=341$; for the NE (SW) zone $r=0.98(0.97), p<0.001)$. As Terra has the longest time series (from 2000), we used only this sensor, and studied the nine years from 2000 to 2008 . However, our study does not capture any possible daily cloudiness cycle (e.g. consistent cloud formation in the late afternoon). By examining the in situ pictures mentioned in section 2.3, 
Table 2. Evolution of the El for the SV zone for ten days for which we have several in situ pictures per day

\begin{tabular}{|c|c|c|c|c|c|}
\hline 11 Oct 2004 & $\begin{array}{c}1753 h \\
\text { El_SV = } 0\end{array}$ & $\begin{array}{c}1949 h \\
\text { El_SV = } 0\end{array}$ & $\begin{array}{c}1955 h \\
\text { El_SV }=0\end{array}$ & $\begin{array}{c}2009 \mathrm{~h} \\
\text { El_SV = } 0\end{array}$ & \\
\hline 25 Mar 2006 & $\begin{array}{c}0915 h \\
\text { El_SV }=0\end{array}$ & $\begin{array}{c}1119 h \\
\text { El_SV }=0.5\end{array}$ & & & \\
\hline 27 Mar 2006 & $\begin{array}{c}1513 \mathrm{~h} \\
\text { EI_SV }=1\end{array}$ & $\begin{array}{c}1859 h \\
\text { El_SV }=1\end{array}$ & & & \\
\hline 28 Mar 2006 & $\begin{array}{c}0925 h \\
\text { EI_SV }=0\end{array}$ & $\begin{array}{c}1411 \mathrm{~h} \\
\text { El_SV }=0.5\end{array}$ & $\begin{array}{c}1456 h \\
\text { El_SV }=0\end{array}$ & & \\
\hline 3 May 2007 & $\begin{array}{c}0726 h \\
\text { EI_SV = } 0\end{array}$ & $\begin{array}{c}1507 h \\
\text { EI_SV = } 0\end{array}$ & $\begin{array}{c}1543 \mathrm{~h} \\
\text { El_SV }=0\end{array}$ & & \\
\hline 17 Apr 2008 & $\begin{array}{c}1607 h \\
\text { El_SV }=1\end{array}$ & $\begin{array}{c}1808 \mathrm{~h} \\
\text { El_SV }=1\end{array}$ & & & \\
\hline 21 Apr 2007 & $\begin{array}{c}0706 \mathrm{~h} \\
\text { El_SV = } 0\end{array}$ & $\begin{array}{c}\text { O719h } \\
\text { EI_SV = 0 }\end{array}$ & $\begin{array}{c}1118 \mathrm{~h} \\
\text { El_SV }=0\end{array}$ & $\begin{array}{c}1520 \mathrm{~h} \\
\text { EI_SV }=0\end{array}$ & $\begin{array}{c}1526 h \\
\text { EI_SV }=0\end{array}$ \\
\hline 26 Apr 2007 & $\begin{array}{c}1532 h \\
\text { El_SV }=1\end{array}$ & $\begin{array}{c}1711 \mathrm{~h} \\
\text { El_SV }=1\end{array}$ & & & \\
\hline 27 Apr 2007 & $\begin{array}{c}\text { O736h } \\
\text { El_SV =1 }\end{array}$ & $\begin{array}{c}0752 h \\
\text { El_SV }=0.5\end{array}$ & $\begin{array}{c}1334 \mathrm{~h} \\
\text { EI_SV =0 }\end{array}$ & $\begin{array}{c}1541 \mathrm{~h} \\
\text { El_SV }=0\end{array}$ & \\
\hline 29 Apr 2007 & $\begin{array}{c}1059 \mathrm{~h} \\
\text { El_SV }=0.5\end{array}$ & $\begin{array}{c}1129 \mathrm{~h} \\
\text { El_SV }=0.5\end{array}$ & & & \\
\hline
\end{tabular}

we find ten days for which we have several pictures per day. Table 2 shows the intra-day El evolution for the SV zone. The cloudiness is near constant, except for 29 April 2007 when the nebulosity disappears during the day.

2. The NE zone is a mountainous area and might not reflect the regional cloudiness eastwards. Similarities between this zone and the SV zone could thus arise from the NE zone definition.

3. We are aware that this approach does not give any information about precipitation rate, as there is no basic relationship between precipitation and cloudiness in this mountainous area owing to orographic cloud formation (Rasmussen and others, 2007). However, whilst cloud cover does not imply precipitation, precipitation cannot occur without clouds. We therefore wish to determine whether there is an exceptionally low cloudiness on this highest glacier that could partly explain a reduced precipitation rate. Nonetheless, we have examined for each zone and each year the correlation between the daily Els and ERA-I precipitation rate (no precipitation data exist in our studied zone) (Berrisford and others, 2009). The correlation, $r$, is always higher than 0.5 and never lower than 0.63 for the SV zone except in 2003 (0.58) $(p<0.001)$. It is also interesting to note that the lowest monthly El occurs during February (Fig. 3) which also records the lowest precipitation rate from 2000 to 2008 according to ERA-I reanalyses (for the NE zone, $4.3 \%$ of annual mean precipitation, the highest contribution being $\sim 12 \%$ in June). Although we do not believe that this comparison with precipitation reanalyses provides a robust test, because of the poor quality of precipitation reanalyses in this region, we think it is worth mentioning it.

4. Finally, we consider an important limitation concerning ice crystal clouds (cirrus) that are considered as nonprecipitating. Indeed, part of our study could be biased because our approach deals with vertically integrated satellite images. As we were able to distinguish icy clouds, an El of 0 ('clear') was assigned where we observed only this type of cloud (for the SV zone, 10-15\%). The comparison with in situ pictures (section 2.3) confirms that we can attribute an El of 0 when only cirrus is detected. However, some cloudy situations ( $\sim 10 \%$ for the SV zone) correspond to a superimposition of different types of cloud, so we may attribute as a cloudy case for the SV zone the situation corresponding to a low cloud cover on the icefield, a clear San Valentín summit and icy clouds at high altitude.

\section{RESULTS AND DISCUSSION}

Our definition of El leads to 27 possible permutations. Their mean annual occurrences from 2000 to 2008 are shown in Figure 4 . The ten most frequent cases $\left(>7 \mathrm{a}^{-1}\right)$ represent $87.8 \%$ of the total occurrences (Fig. 4 legend). The dominant situation is a cloud cover over the three zones $(34.4 \%$ of annual occurrences (e.g. Fig. 1c)), and the second most common is a global clear sky $(17.1 \%$ of annual occurrences (e.g. Fig. 1e)). If we also account for the global mixed situation ( $\mathrm{EI}=0.5$ for the three zones), our observations show that a homogeneous cloudiness over the three zones occurs for more than half the year $(54.4 \%)$. As an initial response to our question, we also examine the occurrence of the case for which EI_SV $=0$ and $\mathrm{EI}=1$ for both the SW and NE zones (e.g. Fig. $1 \mathrm{~d}$ and easily detectable). This case only represents $1.9 \%$ of the total occurrences $\left(7.34 \mathrm{a}^{-1}\right)$ and no seasonality is detected (Fig. 5).

Interestingly, the two dominant cases (the three cloudy or clear zones) exhibit a similar seasonality, with higher occurrence during the austral winter (up to $40 \%$ and $25 \%$ respectively), i.e. in the rainiest season (Fig. 5). This is in agreement with our knowledge of the precipitation regime in the region. During the austral winter, the subpolar low is more intense. This situation combined with the equatorial 


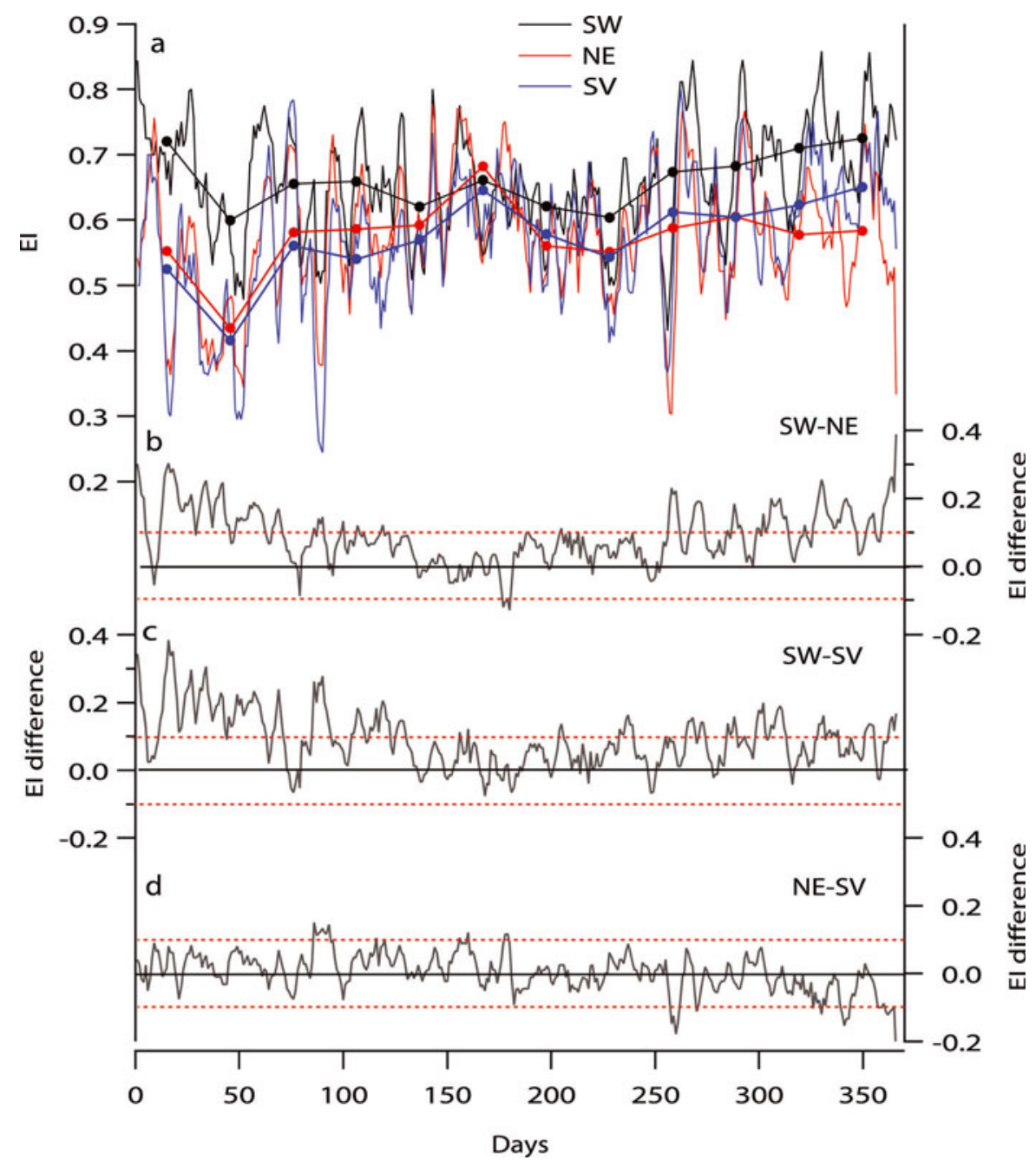

Fig. 3. (a) 5 day running average and monthly mean (represented through color-related dots) of the daily El over the mean period 2000-08 (black curve: SW; red curve: NE; blue curve: SV). The curves are interrupted where no MODIS data were available (e.g. before February 2000). (b-d) The El differences between the three zones computed from the 2000-08 El means.

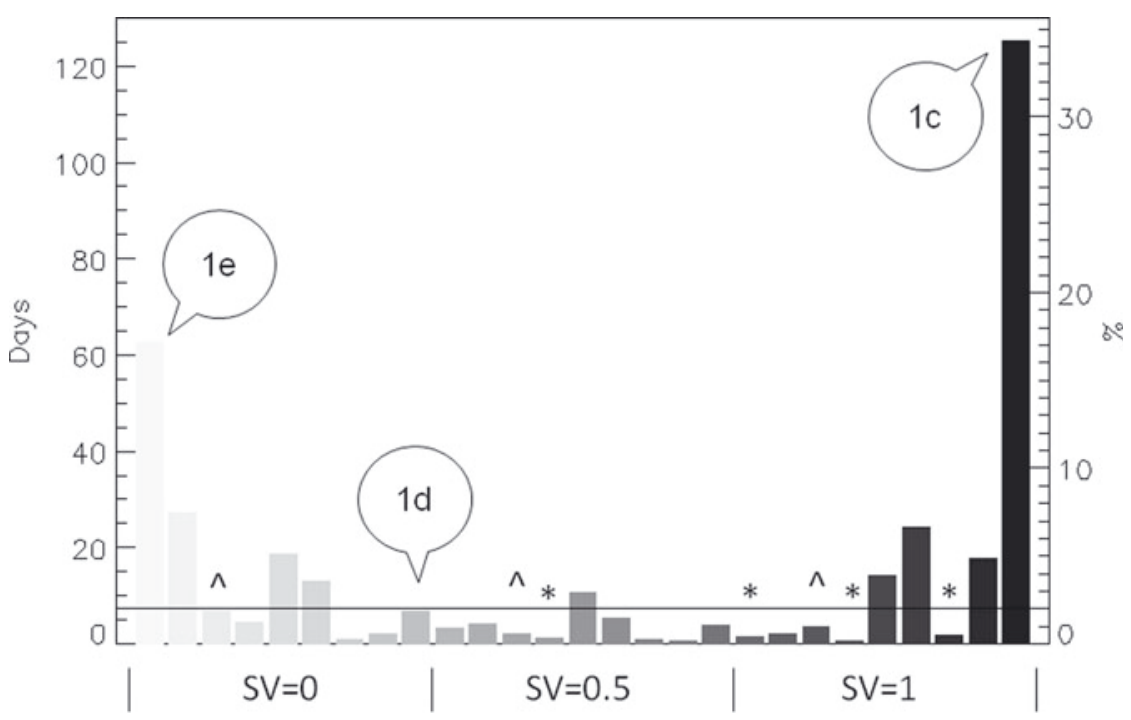

Fig. 4. Occurrences of the 27 El cases over the 2000-08 period in days (left axis) and in per cent (right axis). The occurrences are classified following the EI_SV (0, 0.5 and 1$)$ from left to right. In each section, the increment is of 0.5 for the SW zone and then for the NE zone (NE-SW El in each section are classified as follows: $0-0 ; 0-0.5 ; 0-1 ; 0.5-0 ; 0.5-0.5 ; 0.5-1 ; 1-0 ; 1-0.5 ; 1-1$ ). The ten more frequent situations $\left(>7 \mathrm{a}^{-1}\right.$ ) are above the black line (following the SV-NE-SW classification, they are: $1-1-1,34.4 \% ; 0-0-0,17.1 \% ; 0-0-0.5,7.5 \%$; $1-0.5-1,6.6 \%$; $0-0.5-0.5,5.1 \% ; 1-1-0.5,4.8 \% ; 1-0.5-0.5,3.9 \% ; 0-0.5-1,3.6 \% ; 0.5-0.5-0.5,2.9 \% ; 0-1-1,1.9 \%)$. We also indicate the cases that could reflect the role of the Andes as an orographic barrier as ' $\wedge^{\prime}$ (three cases with El_SW $=1$ and El_NE $=0$ ) and the cases of possible orographic clouds as $^{{ }^{* \prime} \prime}$ (three cases as EI_SW =0 and El_SV =1 and one case as El_SW=0; El_SV and EI_NE =0.5). 

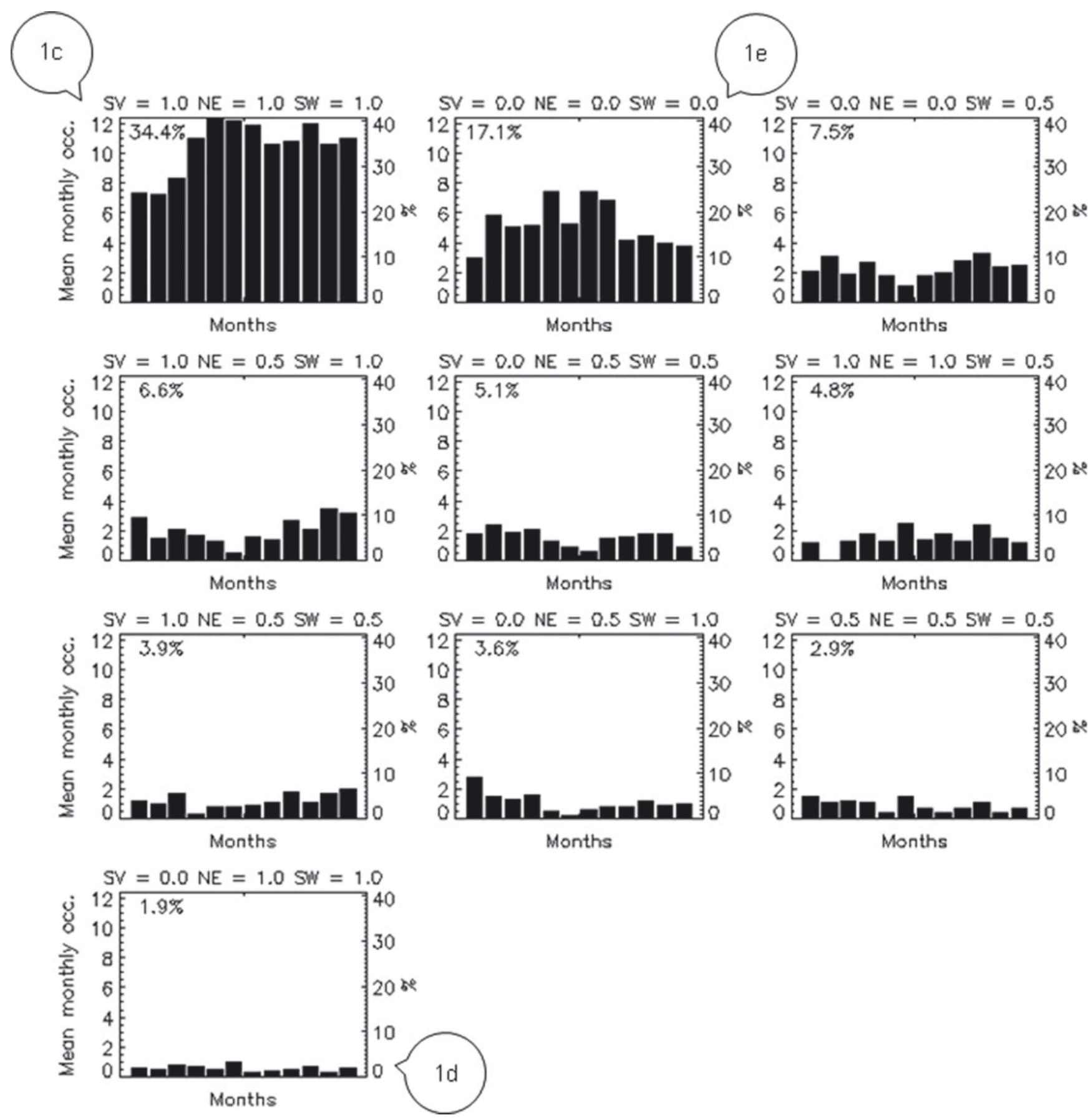

Fig. 5. Seasonal variations of the ten most frequent cases as mentioned in Figure 4 and representing $87.8 \%$ of total annual occurrences. The cases illustrated in Figure 1 are also shown.

displacement of the Pacific high and with ocean temperatures that are higher than continental temperatures, leads to an increase in precipitation over Patagonia that could explain a more frequent homogeneous cloud cover at a regional scale. However, this period also corresponds to southerly and southeasterly advections that are four times more frequent (Schneider and others, 2003) and associated with clear sky (Paruelo and others, 1998). This confirms that our study can capture some linkage variations between precipitation regime and cloudiness.

We have also calculated the temporal El evolution (Fig. 3) over the 2000-08 period to explore the evolution of cloudiness during the year for each zone. Significant correlations $(p<0.001)$ between the three indices are calculated for both daily $\left(S W-N E, r^{2}=0.46\right.$; SW-SV, $\left.r^{2}=0.36 ; N E-S V, r^{2}=0.56\right)$ and monthly (SW-NE, $r^{2}=0.14 ;$ SW-SV, $\left.r^{2}=0.31 ; N E-S V, r^{2}=0.72\right)$ timescales. The differences between the 5 day running average EI only vary between -0.2 and +0.4 (Fig. $3 b-d$ ), revealing, as above, that the SV zone does not have a significantly different cloudiness. This holds true throughout the year, and specifically during the rainiest season when differences only vary between -0.1 and +0.1 (Fig. $3 c$ and $d$ ).

The temporal evolution also illustrates an interesting observation. The SW zone is slightly cloudier than the two other zones, especially during austral summer (EI differences are positive for most of the time, between 0 and +0.4 ; Fig. $3 \mathrm{~b}$ and c), while the annual cloudiness histories for the NE and $\mathrm{SV}$ zones are very close (EI differences are between -0.1 and +0.1 all year; Fig. 3d). Three reasons can be identified: 


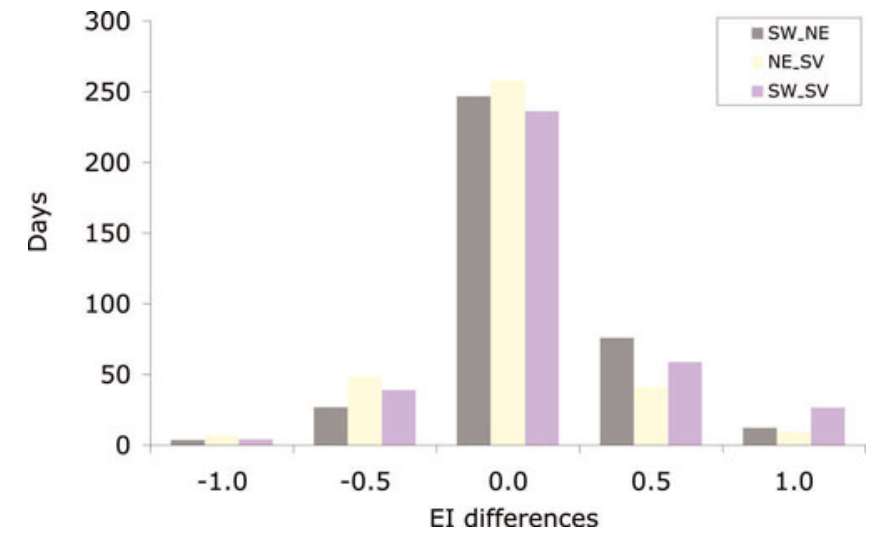

Fig. 6. Histograms of the differences of the El for the mean 2000-08 period between the three zones.

1. A higher frequency of westerlies during the austral summer according to ERA-I reanalyses, leading to more advected humidity from the Pacific Ocean (Castañeda and others, 2008). This presence of additional water in the SW zone atmosphere is confirmed by (a) a clear seasonal cycle in the specific humidity $\left(\Delta_{\text {seas }}=0.06 \mathrm{~kg}\right.$ $\mathrm{kg}^{-1}$ ) from the ERA-I reanalyses over the 2000-07 mean period, with maximum values from December to March $\left(\sim 0.016 \mathrm{~kg} \mathrm{~kg}^{-1}\right)$; (b) a clear seasonal cycle in precipitable water $\left(\Delta_{\text {seas }}=0.8 \mathrm{~g} \mathrm{~cm}^{-2}\right)$ from PARASOL satellite cloud products (we downloaded from the ICARE Data and Services Center the PARASOL hdf monthly Cloud Cover product, available from 2005 to 2007 at a spatial resolution of $18 \mathrm{~km}$; higher than the MODIS cloud products available at $0.5^{\circ}$ resolution (Parol and others, 2008)), with maximum values from November to March $\left(\sim 1.3 \mathrm{~g} \mathrm{~cm}^{-2}\right)$; and (c) a clear seasonal cycle in the Rayleigh pressure $\left(\Delta_{\text {seas }}=100 \mathrm{hPa}\right)$ from PARASOL cloud products from October to March, up to $650 \mathrm{hPa}$, suggesting a lower mean cloud altitude.

2. A barrier effect of the Andes with a well-known effect on the west-east precipitation gradient. Interestingly, the eight cases (among the ten more frequent cases) with occurrences varying from $7.5 \%$ to $1.9 \%$ (Figs 4 and 5 ) all correspond to EI_SW $>0$, showing also the importance of a yearly presence of cloud cover over the SW region. However, Figure 4 shows that the three cases strictly reflecting the Andes as an orographic barrier (defined as EI_SW $=1$ and EI_NE =0) are very uncommon (3.5\%). This proportion increases to $13.8 \%$ if we consider the formation of isolated clouds (orographic clouds) at the San Valentín summit (cases with El_SW $=0$ and either EI_SV $=1$ or El_SV and EI_NE=0.5). Another way to discuss the barrier effect is to compare, for the 2000-08 mean period, the daily El differences between two adjacent zones (SW and SV; NE and SV) (Fig. 6). We see that two adjacent regions present the same state ('clear', 'cloudy' or 'mixed') $68 \%$ of the time. This is particularly true for the NE and SV zones (71\%), with only a very few cases of opposite detection (less than ten 'clear' versus 'cloudy', i.e. 4.6\%). This could be due to the definition of the two zones (section 2.4). The comparison between the SW and the SV zone shows $65 \%$ of similar cases. However, a significant number of positive adjacent cases (EI_SW - EI_SV $=+0.5$ or +1 , i.e. SW zone is cloudier) are observed (24\%). This could reflect the barrier effect: the positive and negative adjacent cases for the NE-SV difference are equivalent $(14 \%$ and $15 \%$ respectively) whereas these values are $24.1 \%$ and $8.3 \%$ respectively when considering the SW-NE difference.

3. The local orography in the SW zone. A coastal mountain and numerous fjords (Fig. 1) could create fog at the start of the afternoon (Cereceda and Schemenauer, 1991) that could be assigned to cloud when scanning satellite images.

\section{CONCLUSIONS AND IMPLICATIONS FOR PALEOCLIMATE STUDIES}

Our initial question deals with the possibility of an unusually low cloudiness over the San Valentín summit, in comparison with surroundings, possibly leading to a low precipitation rate and explaining in part the very low accumulation at that site (Vimeux and others, 2008). Using daily MODIS satellite images from 2000 to 2008, we clearly exclude this hypothesis. We show that the San Valentín summit cloud cover is generally similar to the regional cloudiness (54\%) and that the situation where the San Valentín summit is clear while the surrounding regions are cloudy is very uncommon, accounting for $<2 \%$ of annual occurrences. It is worth noting that the use of the $\mathrm{Cl}$ leads to similar conclusions.

Our results are not consistent with pilots' oral reports. We also have in situ pictures showing the San Valentín summit protruding through a lower cloud cover. We suggest that this situation is subconsciously the most spectacular and most memorable. More systematic observations carried out with airplane pilots could help to validate our study.

Wind erosion and snow redeposition are likely to be the main processes controlling the net accumulation at this location. This conclusion is consistent with the accumulation rate observed during field operations in March-April 2006 (several meters of snowfall over 24 hours, though no measurement was made due to the extreme meteorological situation; personal communication from P. Ginot, 2006). It is nonetheless important to keep in mind that our approach deals with vertically integrated satellite images, and that no direct relationship between precipitation and cloudiness is established for this mountainous area. This result indicates the difficulty in using reconstructions of the annual net accumulation from ice cores to estimate atmospheric moisture changes in this region, as has been done for the tropical Andes (e.g. Thompson and others, 2006).

Our study also enables us to discuss the barrier effect of the mountain range. We show an impact on cloudiness throughout the year, where the SW zone is slightly cloudier, especially during austral winter. However, we identify no strong blocking since cloudiness in the SW zone is higher than in the SV zone for only $24 \%$ of the time. Again, our approach considers the total vertical cloud cover, so we cannot decipher the barrier effect for low- and high-altitude clouds. As suggested by Barrett and others (2009), the mountain range might only prevent some low-altitude air masses from crossing the Andes, not detectable with our approach. This means that climate history recorded in the San Valentín ice core may not be fully related to changes in the intensity or position of the westerlies. This was also suggested by Vimeux and others (2008) when comparing the marine and continental chemical elements recorded in the 
ice and will have to be accounted for when interpreting the deep ice core $(122 \mathrm{~m})$ drilled in 2007.

Finally, we show that the eye scanning of satellite falsecolor images, which is a very simple methodology, can offer an interesting approach to evaluate cloudiness. The ongoing analyses of several ice cores drilled in 2007 on the San Valentín summit should provide further information on the accumulation type encountered at this high-altitude Patagonian glacier, and will bring information for ice flow modeling at these sites.

\section{ACKNOWLEDGEMENTS}

This work was initiated by fruitful discussions in the framework of the Agence National de la Recherche (France; ANR) SANVALLOR project (ANR-06-BLAN-0245). C.R. was partially funded by the ANR-06-BLAN-0245 project. We thank F.-M. Bréon, F. Chevallier and V. Masson-Delmotte for valuable inputs on the manuscript, and three reviewers for constructive comments. We thank P. Ginot for the pictures of Monte San Valentín shown in Figure 2. The MODIS data are distributed by the Land Processes Distributed Active Archive Center, located at the US Geological Survey (USGS) Earth Resources Observation and Science (EROS) Center (Ipdaac.usgs.gov). We thank the ICARE Data and Services Center for providing access to CNES/PARASOL data.

\section{REFERENCES}

Aristarain, A.J. and R.J. Delmas. 1993. Firn-core study from the southern Patagonia ice cap, South America. J. Glaciol., 39(132), 249-254.

Barrett, B.S., R.D. Garreaud and M. Falvey. 2009. Effect of the Andes Cordillera on precipitation from a midlatitude cold front. Mon. Weather Rev., 137(9), 3092-3109.

Berrisford, P. and 6 others. 2009. The ERA-Interim archive. Reading, European Centre for Medium-Range Weather Forecasts. (ERA Report Series 1.)

Carrasco, J., G. Casassa and A. Rivera. 2002. Meteorological and climatological aspects of the Southern Patagonia Icefield. In Casassa, G., F. Supúlveda and R. Sinclair, eds. The Patagonian ice fields: a unique natural laboratory for environmental and climate change studies. New York, Kluwer Academic/Plenum Publishers, 29-41.

Castañeda, M. and M. González. 2008. Statistical analysis of the precipitation trends in the Patagonia region of southern South America. Atmósfera, 21(3), 303-317.

Cereceda, P. and R.S. Schemenauer. 1991. The occurrence of fog in Chile. J. Appl. Meteorol., 30(8), 1097-1105.

Escobar, F., F. Vidal, C. Garín and R. Naruse. 1992. Water balance in the Patagonia icefield. In Naruse, R. and M. Aniya, eds. Glaciological researches in Patagonia, 1990. Nagoya, Japanese Society of Snow and Ice. Data Center for Glacier Research, 109-119.

Fujiyoshi, Y., H. Kondo, J. Inoue and T. Yamada. 1987. Characteristics of precipitation and vertical structure of air temperature in the northern Patagonia. Bull. Glacier Res., 4, 15-23.

Hall, D.K., G.A. Riggs and V.V. Salomonson. 1995. Development of methods for mapping global snow cover using Moderate Resolution Imaging Spectroradiometer (MODIS) data. Remote Sens. Environ., 54(2), 127-140.
Kalnay, E. and 21 others. 1996. The NCEP/NCAR 40-year reanalysis project. Bull. Am. Meteorol. Soc., 77(3), 437-471.

Lopez, P., P. Sirguey, Y. Arnaud, B. Pouyaud and P. Chevallier. 2008. Snow cover monitoring in the Northern Patagonia Icefield using MODIS satellite images (2000-2006). Global Planet. Change, 61(3-4), 103-116.

Maignan, F., F.-M. Bréon and R. Lacaze. 2004. Bidirectional reflectance of Earth targets: evaluation of analytical models using a large set of spaceborne measurements with emphasis on the Hot Spot. Remote Sens. Environ., 90(2), 210-220.

Matsuoka, K. and R. Naruse. 1999. Mass balance features derived from a firn core at Hielo Patagónico Norte, South America. Arct. Antarct. Alp. Res., 31(4), 333-340.

Parajka, J. and G. Blöschl. 2006. Validation of MODIS snow cover images over Austria. Hydrol. Earth Syst. Sci., 10(5), 679-689.

Parol, F. and 7 others. 2008. Comparison between POLDER/ PARASOL and MODIS/AQUA operational cloud products. [Abstr. A31E-0175.] Eos., 90(52), Fall Meet. Suppl.

Paruelo, J.M., A. Beltrán, E. Jobbágy, O.E. Sala and R.A. Golluscio. 1998. The climate of Patagonia: general patterns and controls on biotic processes. Ecol. Austral, 8(2), 75-307.

Popovnin, V.V., T.A. Danilova and D.A. Petrakov. 1999. A pioneer mass balance estimate for a Patagonian glacier: Glaciar De los Tres, Argentina. Global Planet. Change, 22(1-4), 255-267.

Rasmussen, L.A., H. Conway and C.F. Raymond. 2007. Influence of upper air conditions on the Patagonia icefields. Global Planet. Change, 59(1-4), 203-216.

Rott, H., M. Stuefer, A. Siegel, P. Skvarca and A. Eckstaller. 1998. Mass fluxes and dynamics of Moreno Glacier, Southern Patagonia Icefield. Geophys. Res. Lett., 25(9), 1407-1410.

Salomonson, V.V. and I. Appel. 2004. Estimating fractional snowcover from MODIS using the normalised difference snow index. Remote Sens. Environ., 89(3), 351-360.

Schneider, C., M. Glaser, R. Kilian, A. Santana, N. Butorovic and G. Casassa. 2003. Weather observations across the Southern Andes at $53^{\circ} \mathrm{C}$. Phys. Geogr., 24(2), 97-119.

Schwikowski, M., S. Brütsch, G. Casassa and A. Rivera. 2006. A potential high-elevation ice-core site at Hielo Patagónico Sur. Ann. Glaciol., 43, 8-13.

Shiraiwa, T. and 6 others. 2002. High net accumulation rates at Campo de Hielo Patagónico Sur, South America, revealed by analysis of a $45.97 \mathrm{~m}$ long ice core. Ann. Glaciol., 35, 84-90.

Shreve, C.M., G.S. Okin and T.H. Painter. 2009. Indices for estimating fractional snow cover in the western Tibetan Plateau. J. Glaciol., 55(192), 737-745.

Thompson, L.G. and 8 others. 2006. Abrupt tropical climate change: past and present. Proc. Natl. Acad. Sci. USA (PNAS), 103(28), 10,536-10,543.

Vermote, E.F., N.Z. El Saleous and C.O. Justice. 2002. Atmospheric correction of MODIS data in the visible to middle infrared: first results. Remote Sens. Environ., 83(1-2), 97-111.

Villalba, R. and 9 others. 2003. Large-scale temperature changes across the southern Andes: 20th-century variations in the context of the past 400 years. Climatic Change, 59(1-2), $177-232$

Vimeux, F. and 7 others. 2008. A promising location in Patagonia for paleoclimate and paleoenvironmental reconstructions revealed by a shallow firn core from Monte San Valentín (Northern Patagonia Icefield, Chile). J. Geophys. Res., 113(D16), D16118. (10.1029/2007JD009502.)

Yamada, T. 1987. Glaciological characteristics revealed by $37.6-\mathrm{m}$ deep core drilled at the accumulation area of San Rafael Glacier, the Northern Patagonia Icefield. Bull. Glacier Res., 4, 59-67. 